
\title{
ОСОБЕННОСТИ СИНДРОМА ЭМОЦИОНАЛЬНОГО ВЫГОРАНИЯ У СТУДЕНТОВ ПЕДАГОГИЧЕСКОГО НАПРАВЛЕНИЯ
}

\section{EATURES OF EMOTIONAL BURNOUT SYNDROME IN STUDENTS OF PEDAGOGICAL DIRECTION}

I. Shakhmalova

L. Mamedova

D. Kabardaeva

Summary: This article discusses the features and stages of emotional burnout syndrome as a psychological and pedagogical phenomenon. The results of a theoretical and empirical study of burnout syndrome in 3rd-year students of the technical Institute (f) «North-Eastern Federal University» in Neryungri are presented. The authors used diagnostics of emotional burnout (V. V. Boyko) and diagnostics of emotional burnout (K. Maslach, S. Jackson, adapted by N.E. Vodopyanova). The authors found that students are characterized by emotional reflection of discontent and internal discomfort. It also considers preventive measures to reduce the burnout syndrome in students of the pedagogical direction.

Keywords: burnout syndrome, students, diagnostics, level, prevention.
Шахмалова Ирина Жаповна

к.п.н., дочент, ФГАОУ ВО «Северо-Восточный федеральный университет", Технический институт (филиал) $P($ (Я)

2. Нерюнгри

irinashachmaiova@mail.ru

Мамедова Лариса Викторовна

к.п.н., доцент, ФГАОУ ВО «Северо-Восточный федеральный университет», Технический институт (филиал) PC(Я) г. Нерюнгри

larisamamedova@yandex.ru

Кабардаева Диана Арсеновна

ФГАОУ ВО «Северо-Восточный федеральный университет», Технический институт (филиал) $P((Я)$,

2. Нерюнгри

dkabardaeva@mail.ru

Аннотация: В данной статье рассматриваются особенности и стадии синдрома эмоционального выгорания, как психолого-педагогического явления. Представлены результаты теоретического и эмпирического исследования синдрома эмоционального выгорания у студентов 3 курса Технического института $(\phi)$ «Северо-Восточный федеральный университет» в г. Нерюнгри. Авторами использованы диагностика эмоционального выгорания личности (В.В. Бойко) и диагностика эмоционального выгорания (К. Маслач, С. ДжекСон, В адаптации Н.Е. Водопьяновой). Авторами выявлено, что для студентов характерно эмоциональное отражение недовольства и внутренний дискомфорт. Также рассматриваются профилактические меры по снижению синдрома эмоционального выгорания у студентов педагогического направления.

Ключевые слова: синдром эмоционального выгорания, студенты, диагностика, уровень, профилактика.

нальном напряжении, чувстве нехватки сил до конца рабочего дня и на следующий день, и, как результат - в снижении эмоционального фона.

Вторая стадия проявляется в чувстве раздражения к окружающим людям, коллегам по работе, теряется интерес к общению. В коллективе, человек который начинает «эмоционально выгорать» может начать негативно отзываться о людях, которые его окружают (коллеги, подчиненные, клиенты).

Третья стадия эмоционального выгорания проявляется довольно резким падением самооценки, которая может проявиться в негативном оценивании самого себя, своих профессиональных достижений и успехов $[5,8,9]$.

Можно сделать вывод, что сущность эмоционального выгорания заключается в ответной реакции на длительное стрессовое влияние общения с окружающими. 
Эмоциональное выгорание зачастую можно встретить у педагогов, так как их профессиональная деятельность связана с высокой производительностью и напряженностью труда, широким спектром профессиональных обязанностей и требований, а также повышенной ответственностью за результаты образования.

Целью нашего исследования является выявление особенностей эмоционального выгорания студентов 3 курса Технического института.

Для исследования эмоционального выгорания студентов были использованы:

1. Диагностика эмоционального выгорания личности (В.В. Бойко) [3];

2. Диагностика эмоционального выгорания (К. Маслач, С. Джексон, в адаптации Н.Е. Водопьяновой).

В рамках данного исследования были исследованы студенты третьего курса обучающиеся по очной форме обучения по направлению подготовки «Педагогическое образование». В исследовании приняли участие 15 человек, из них 10 девушек, 5 юношей.

Результаты исследования уровня эмоционального выгорания у студентов по методике В.В. Бойко указывают, что переживание психотравмирующих обстоятельств на уровне сложившегося симптома сформировано у 9 испытуемых, что составляет $60 \%$ от общего числа участников исследования. Значения на уровне не сложившегося симптома выявлены у 2 студентов, что составляет 13,3\% от общего числа испытуемых. При этом значения на уровне складывающегося симптома характерны еще для $26,7 \%$ участников исследования (4 человека).

Другим симптомом, который выявлен у студентов, является «загнанность в клетку», на уровне сложившегося симптома он сформирован у 8 испытуемых, что составляет $53,3 \%$ от общего числа участников исследования. Для 26,7\% студентов (4 человека), принимавших участие в исследовании, характерно проявление симптома как складывающегося. Также значения на уровне не сложившегося симптома характерны для 13,3\% студентов (2 человека).

Полученные данные в фазе «напряжение» выражены симптомом неудовлетворенности собой у 53,3\% студентов, принимавших участие в исследовании; симптомы тревоги и депрессии также у 46,7\% студентов изучаемой группы. Ведущим симптомом выгорания у студентов в фазе «напряжение» является переживание психотравмирующих обстоятельств.

Результаты полученные в фазе «резистенция» указывают на симптом редукции профессиональных обязанностей, на уровне сложившегося симптома у 10 ис- пытуемых, что составляет 66,6\%, из них на уровне не сложившегося симптома зафиксированы значения у 5 испытуемых, что соответствует 33,3\% от общего числа участников исследования.

Характеризуя у студентов сложившиеся и доминирующие симптомы в фазе «резистенция», можно отметить, что симптом эмоционально-нравственной дезориентации у студентов изучаемой группы является сложившимся у 73,3\% (11 студентов), из них 26,7\% (4 студента) от общего количества участников имеют значения, указывающие на складывающийся симптом.

Расширение сферы экономии эмоций на уровне сложившегося симптома представлено у 9 испытуемых, что соответствует 60\%, из них на уровне не сложившегося симптома 6 испытуемых, что составляет 40\% от общего числа участников.

В фазе «истощение» полученные данные указывают на эмоциональный дефицит на уровне сложившегося симптома у 8 испытуемых, что составляет 53,3\% от общего числа участников исследования. Значения на уровне не сложившегося симптома получены у 3 испытуемых, что составляет 20\%. Результаты на условнее складывающегося симптома выявлено у 26,7\% (4 студента) от общего числа испытуемых.

В фазе «истощение» эмоциональная отстраненность на уровне не сложившегося симптома у студентов изучаемой группы представлена у 2 человек, что составляет 13,3\%. Значения показателя на уровне сложившегося симптома представлены у 9 студентов, что соответствует $60 \%$ от общего числа участников. На уровне складывающегося симптома получены результаты у 4 студентов, что составляет $26,7 \%$.

Личностная отстраненность на уровне сложившегося симптома проявляется у 53,3\% студентов (8 человек). На уровне складывающегося симптома этот показатель выявлен у 6 испытуемых, что составляет $40 \%$ от общего числа участников. Результаты, полученные на уровне не сложившегося симптома выявлены у 2 студентов, что составляет $13,3 \%$.

Психосоматические и психовегетативные нарушения на уровне сложившегося симптома представлены у 7 студентов, что составляет $46,7 \%$ от общего числа участников, среди которых несложившийся симптом обнаружен у 6 испытуемых, что составляет 40\% от общего числа испытуемых. Уровень складывающегося симптома оказался незначительным.

Исходя из полученных данных, можно сделать вывод, что в фазе «напряжение» преобладающим симптомом является переживание психотравмирующих об- 
стоятельств, а остальные симптомы сформированы или имеют стадию формирования. В фазе «резистенция» доминирующими является симптом «редукции профессиональных обязанностей». Остальные симптомы в данной фазе синдрома эмоционального выгорания представлены у студентов в меньшей степени, но имеются как на уровне сложившегося симптома, так и складывающегося. Полученные значения говорят о том, что фаза «напряжения» сформировалась у 55\% от общего числа испытуемых, находится на фазе формирования у 23,3\% студентов, а несформированная фаза составляет 21,7\% от общего числа участников.

Фаза «резистенция» не сформировалась у 23,3\% от общего числа испытуемых. Однако формируется у 8,3\% и сформировалась у 68,3\% от общего числа участников исследования.

Фаза «истощение» не сформировалась 21,7\%, формируется у $25 \%$ от общего числа испытуемых, а является сформированной у $53 \%$ участников.

На рисунке 1 графически представлены результаты исследования эмоционального выгорания у студентов.

Таким образом, мы видим, что самой многочисленной оказалась группа студентов со сформировавшейся фазой, по сравнению с формирующейся и несформировавшейся фазами эмоционального выгорания. Стоит отметить, что важно уделить внимание тем симптомам и фазам, которые уже сформированы и доминируют. С ними и нужно работать.

После проведения и обработки результатов первой диагностики, мы приступили к изучению, проведению и подготовки результатов по второй методике.

Результаты исследования уровня эмоционального выгорания у студентов по методике К. Маслач, С. Джексон в адаптации Н.Е. Водопьяновой представлены в таблице 1.

Таким образом, согласно полученным данным по шкале «эмоциональное истощение» 39,6\% испытуемых продемонстрировали очень низкий уровень, а 29,2\% показали средний уровень данного показателя. Следо-

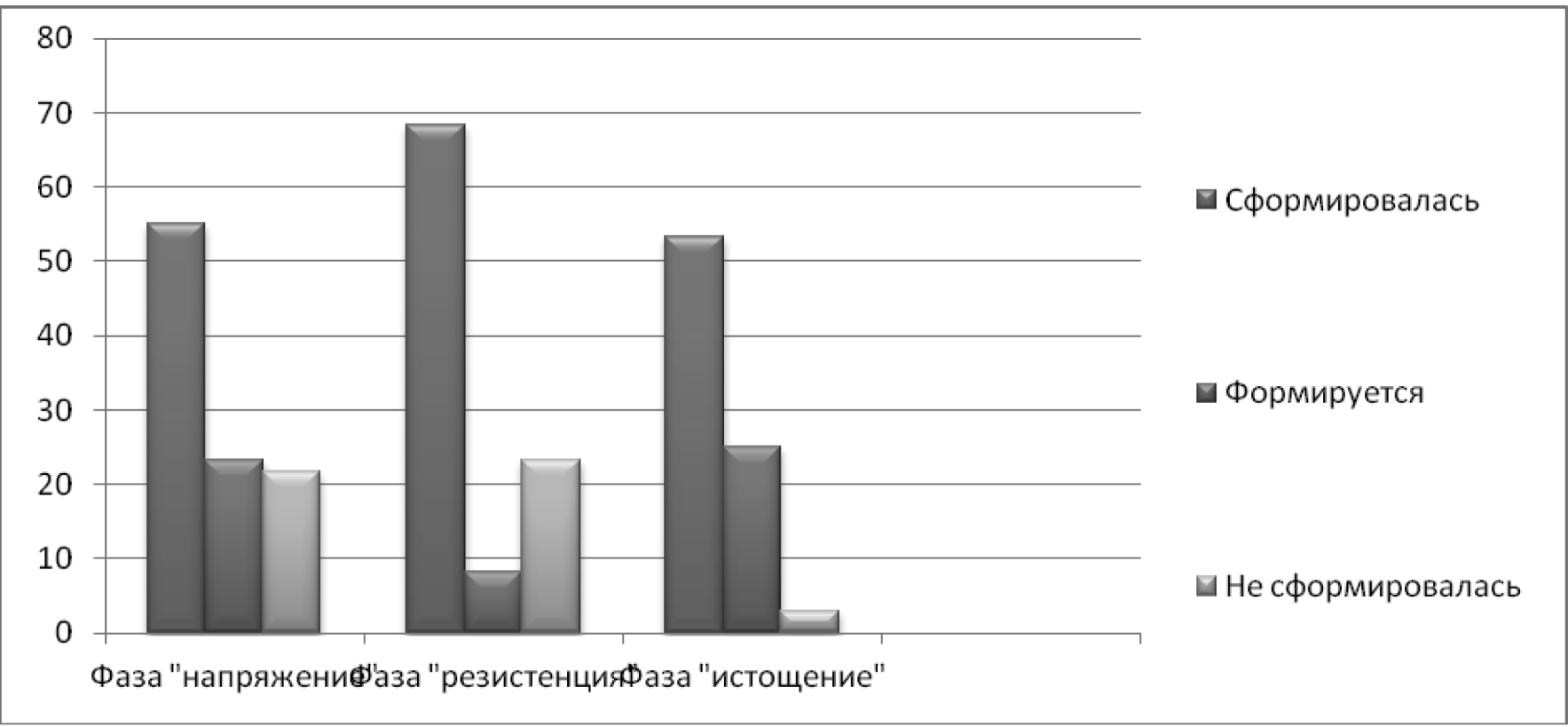

Рис. 1. Соотношение групп студентов по сформированности фаз эмоционального выгорания

Таблица 1

Уровни эмоционального выгорания (в \%)

\begin{tabular}{|c|c|c|c|c|c|}
\hline Шкала & Очень низкий уровень & Низкий уровень & Средний уровень & Высокий уровень & Очень высокий уровень \\
\hline Шкальные оценки & 1 & 2 & 3 & 4 & 5 \\
\hline $\begin{array}{c}\text { Эмоциональное } \\
\text { истощение }\end{array}$ & 39,6 & 16,7 & 29,2 & 8,3 & 6,2 \\
\hline Деперсонализация & 32,1 & 32,1 & 28,6 & 7,2 & 0 \\
\hline $\begin{array}{c}\text { Профессиональная } \\
\text { успешность }\end{array}$ & 5,8 & 7,9 & 29 & 31,6 & 25,1 \\
\hline
\end{tabular}


вательно, это указывает на стабильный эмоциональный фон, отсутствие эмоционального перенапряжения и чувства опустошенности, поддержки собственных эмоциональных ресурсов на достаточно положительном уровне.

По шкале «деперсонализация» 32,1\% опрошенных показали очень низкий и низкий уровни, а 28,6\% показали средний уровень данного показателя, высокий уровень показало незначительное количество опрошенных. Это говорит о том, что у этих опрошенных прослеживается тенденция к развитию позитивного, душевного, доброжелательного отношения к окружающим.

По шкале «редукция личных достижений» 29\% испытуемых продемонстрировали средний уровень, 31,6\% показали высокий уровень, а 25,1\% опрошенных показали очень высокий уровень данного показателя, что указывает на положительное отношение к самому себе, адекватное оценивание (без завышения и занижения) своих профессиональных достижений и успехов.

Согласно значению показателя низкая степень эмоционального выгорания представлена у меньшей части от общего числа студентов, которые принимали участие в исследовании. Средняя степень эмоционального выгорания характерна для 29 \% участников опроса. Высокая степень выраженности интегрального показателя выявлена у $11,8 \%$ от общего числа испытуемых и крайне высокая степень эмоционального выгорания обнаружена у 9 студентов, что составляет 18,4\%.

Выявленные особенности эмоционального выгорания студентов 3 курса помогли определить необходимость профилактики синдрома эмоционального выгорания студентов.

Переживания и стрессы, которые связаны с учебой, довольно часто возникают в случаях, когда студенты не способны справиться с требованиями, которые предъявляются им в учебных заведениях. Для того, чтобы справиться со всеми эмоциональными нагрузками современной жизни, в которых студентам приходится существовать, необходимо проводить комплекс профилактически мероприятий по эмоциональному выгоранию.

В психологической практике профилактики синдрома эмоционального выгорания можно выделить просветительское направление и личностные тренинги направление на развитие личностных ресурсов.

Прежде всего, студентам необходимо научиться планировать свое время, режим труда и, соответственно, отдыха - перерывы в течение учебного дня могут помочь поддерживать энергию на протяжении дня и восстанавливать силы.

Тренинги на развитие личностных ресурсов должны включать развитие психологической компетентности, уровня психологической грамотности и культуры; активной мотивации преодоления, отношение к стрессам как возможности приобретения личного опыта и возможности личностного роста; адекватной и высокой самооценки; позитивность и рациональность мышления и т.д.

Таким образом, уровень синдрома эмоционального выгорания у студентов 3 курса соответствует выше среднему. Для данного уровня характерно эмоциональное отражение недовольства и внутренний дискомфорт респондентов, злоба и агрессия в отношениях с людьми, с которыми необходимо общаться на протяжении всего дня. Во избежание агрессии, студенты могут отстраняться от окружающих, замыкаться в себе и выполнять минимум работы и не проявлять активности, для того, чтобы меньше контактировать с окружающими людьми. Для того, чтобы не допустить роста уровня синдрома эмоционального выгорания, студентам необходимо четко планировать свой день, правильно оценивать свои силы и заботиться о своем здоровье. Разработка комплекса профилактических мероприятий по снижению синдрома эмоционального выгорания станет предметом нашего дальнейшего исследования.

\section{ЛИТЕРАТУРА}

1. Березовская Л.Г., Слабинский В.Ю., Подсадный С.А. К вопросу критериев риска развития синдрома «эмоционального выгорания». СПб.: Санкт-Петербургская государственная медицинская академия им. И.И. Мечникова, 2007. - 189 с.

2. Безносов С.П. Профессиональная деформация личности. СПб.: Речь, 2004. 272 с.

3. Бойко В.В. Методика диагностики уровня эмоционального выгорания // Практическая психодиагностика / ред. Д.Я. Райгородского. Самара, 1999. - 120 с.

4. Бойко В.В. Синдром эмоционального выгорания в профессиональном общении. СПб., 2009. 278 с.

5. Водопьянова Н.Е. Синдром выгорания. Диагностика и профилактика. СПб.: Питер, 2009. 336 с.

6. Горшков Е.А. Исследование синдрома эмоционального выгорания у студентов-старшекурсников // Молодой ученый. 2015. № 23. С. 51-55

7. Гришина Н.В. Помогающие отношения: профессиональные и экзистенциальные проблемы // Психологические проблемы самореализации личности / под ред. А.А. Крылова и Л.А. Коростылевой. СПб.: Питер, 2000. 256 с.

8. Изотова Е.Г. Специфика синдрома эмоционального выгорания у учителей средней школы// Дошкольное и начальное образование: варьирование подходов в условиях смены образовательных парадигм: материалы междун. Конф. «Чтения Ушинского», пед. фак. ЯГПУ. - Ярославль: Изд-во ЯГПУ, 2013 - Ч.1 
9. Лапина И.А. Эмоциональное выгорание: причины, последствия /И.А. Лапина. // Молодой ученый. - 2016 - №29 (133) - URL: https://moluch.ru/ archive/133/37222/ (дата обращения - 16.10.2020г.)

10. Очирова Е.А., Дугарова Т.Ц. Эмоциональная напряженность как фактор психологической дезадаптации студентов 1 курса//сборник материалов III Всероссийской научно-практической конференции студентов и аспирантов. Северо-Восточный федеральный университет им. М.К. Аммосова. Киров. 2014. C. 246-248.

11. Профилактика синдрома эмоционального выгорания педагогов: диагностика, тренинги, упражнения / авт. - сост. 0.И. Бабич. - Изд. 2-е. - Волгоград.2018. 122 c.

12. Maslach C, Jackson SE, Leiter MP. Maslach Burnout Inventory Manual. 3rd ed. California: CPP, Inc; 1996.

( ) Шахмалова Ирина Жаповна (irinashachmaiova@mail.ru ), Мамедова Лариса Викторовна (larisamamedova@yandex.ru ),

Кабардаева Диана Арсеновна (dkabardaeva@mail.ru).

Журнал «Современная наука: актуальные проблемы теории и практики»

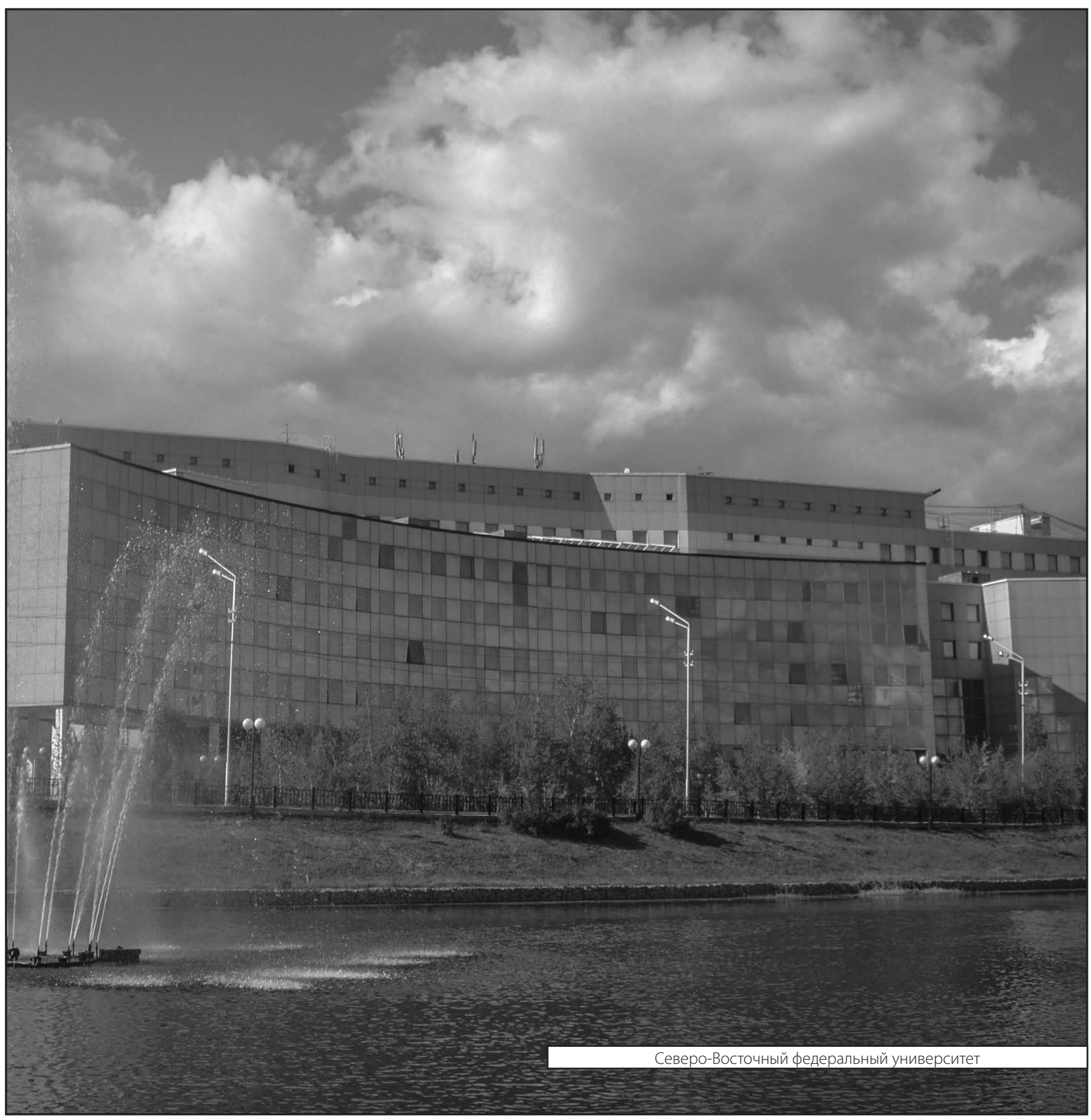

